NOTE

\title{
First microsatellite loci of the myxozoan parasite Tetracapsuloides bryosalmonae, the causative agent of proliferative kidney disease (PKD)
}

\author{
Hanna Hartikainen ${ }^{1,2}$, Dmitry Filippenko ${ }^{3,4}$, Beth Okamura ${ }^{1}$, Anti Vasemägi ${ }^{3,5, *}$ \\ ${ }^{1}$ Department of Life Sciences, Natural History Museum, London SW7 5BD, UK \\ ${ }^{2}$ ETH and Eawag, Institute for Integrative Biology, Ueberlandstrasse 133, 8600 Duebendorf, Switzerland \\ ${ }^{3}$ Division of Genetics and Physiology, Department of Biology, University of Turku, 20014 Turku, Finland \\ ${ }^{4}$ Kaliningrad Regional Center for Environment and Tourism, 236006 Kaliningrad, Russian Federation \\ ${ }^{5}$ Department of Aquaculture, Estonian University of Life Sciences, 51014 Tartu, Estonia
}

\begin{abstract}
Proliferative kidney disease (PKD) caused by the myxozoan parasite Tetracapsuloides bryosalmonae is a severe parasitic disease of salmonid fish. Estimates of genetic variation in parasite populations across Europe are currently lacking. We developed the first polymorphic microsatellite markers for T. bryosalmonae using Illumina MiSeq sequence data derived from genomic DNA. Twelve polymorphic loci were identified from 24 tested loci. Allelic variation was low at most loci, ranging from 2 to 6 (average 3.0). The markers developed here are expected to be useful in future genetic studies of $T$. bryosalmonae, aimed at further understanding the dispersal of the parasite, host-parasite relationships and the epidemiology of PKD.
\end{abstract}

KEY WORDS: Fish disease · Brown trout · Parasite · Population genetics · Host-parasite relationship

Tetracapsuloides bryosalmonae is a malacosporean (Phylum Cnidaria) parasite that causes proliferative kidney disease (PKD) of salmonids (Canning et al. 1999). PKD is considered as an emerging disease in the northern hemisphere, causing high mortality and significant losses of fish farm stock and impacting natural populations both in Europe and North America (Okamura et al. 2011, Skovgaard \& Buchmann 2012, Dash \& Vasemägi 2014). The parasite develops in the body cavity of freshwater bryozoans, and mature water-borne spores infect fish via both the gills (Morris et al. 2000, Grabner \& El-Matbouli 2010) and the skin epithelium (Longshaw et al. 2002).
Despite the economic and conservation implications of PKD, only a handful of sequences from T. bryosalmonae have been deposited in GenBank (mostly ribosomal DNA), and there are no polymorphic microsatellite loci available to describe the population genetic structure or identify multiple infections within hosts. Recently, we described a genomic library generated from approximately 1000 T. bryosalmonae sacs collected by dissection from Fredericella sultana (Filippenko et al. 2014). We identified altogether 10653 microsatellite motifs using msatcommander v.1.0.8 software and were able to design primers for 865 microsatellite loci 
using Primer3 software (repeat number 6-47, potential duplicates removed; available as supplementary material Table 1 in Filippenko et al. 2014). By testing 24 tri- and tetranucleotide microsatellite mark- ers from this library, we identified 12 polymorphic markers for $F$. sultana, none of which successfully amplified in $T$. bryosalmonae. However, BLAST searches of small subunit rRNA gene suggested that

Table 1. Characteristics of novel microsatellite loci in Tetracapsuloides bryosalmonae. Forward primer sequences are presented with the M13-tail (5'-3' CACGACGTTGTAAAACGAC). The GTTT 'tail' (Brownstein et al. 1996) was added to the reverse primer. Dashes indicate lack of amplification

\begin{tabular}{|c|c|c|c|c|c|}
\hline $\begin{array}{l}\text { Locus } \\
\text { name }\end{array}$ & Primer sequences $\left(5^{\prime}-3^{\prime}\right)$ & $\begin{array}{l}\text { Motif/ } \\
\text { Repeat }\end{array}$ & $\begin{array}{l}\text { Size } \\
\text { range } \\
(\mathrm{bp})\end{array}$ & $\begin{array}{l}\text { Primer- } \\
\text { label }\end{array}$ & $\begin{array}{c}\text { No } \\
\text { of } \\
\text { alleles }\end{array}$ \\
\hline Tb042TKU & $\begin{array}{l}\text { F: CACGACGTTGTAAAACGACTTGGGAATAATGAAATTTGAAAGA } \\
\text { R: GTTTATTACGGGTTCACTTATTTAGGTATT }\end{array}$ & (AT) 5 & $237-241$ & VIC & 3 \\
\hline Tb043TKU & $\begin{array}{l}\text { F: CACGACGTTGTAAAACGACTGTGCACGAAAACTTTACAAATC } \\
\text { R: GTTTACCCTATCGCCTCAATGAAA }\end{array}$ & (AT) 5 & $311-319$ & NED & 4 \\
\hline Tb044TKU & $\begin{array}{l}\text { F: CACGACGTTGTAAAACGACTTAAACAGTCAAAATAGGCAATCA } \\
\text { R: GTTTCCGATTTCTTATGGAAATACTTCTT }\end{array}$ & (AT) 10 & $220-224$ & PET & 3 \\
\hline Tb045TKU & $\begin{array}{l}\text { F: CACGACGTTGTAAAACGACAGCCATGTAGCCCAAAACAC } \\
\text { R: GTTTATTTGAGGGGATTGCTGTTG }\end{array}$ & (AT) 5 & $521-523$ & 6-FAM & 2 \\
\hline Tb049TKU & $\begin{array}{l}\text { F: CACGACGTTGTAAAACGACGCAGCATCCAATGATGTGTT } \\
\text { R: GTTTCGATTTTTGCGGATCTCAT }\end{array}$ & (AT) 5 & $290-293$ & 6-FAM & 2 \\
\hline Tb054TKU & $\begin{array}{l}\text { F: CACGACGTTGTAAAACGACCCTTTCAATGGCTGAGCAC } \\
\text { R: GTTTCGTAGATCTCAAGTTCCAAACA }\end{array}$ & (AT) 6 & $325-329$ & VIC & 2 \\
\hline Tb055TKU & $\begin{array}{l}\text { F: CACGACGTTGTAAAACGACTACCAACAGCCCAAGGTTTC } \\
\text { R: GTTTGCTTTACCTTGAATTTTCTGTTT }\end{array}$ & (GT) 5 & $335-338$ & NED & 2 \\
\hline Tb058TKU & $\begin{array}{l}\text { F: CACGACGTTGTAAAACGACTCCAGCATTATGATTGTGCAT } \\
\text { R: GTTTAAGTCAAATAAATAAATGGAAGAAAGA }\end{array}$ & (AT) 6 & $185-191$ & VIC & 4 \\
\hline Tb059TKU & $\begin{array}{l}\text { F: CACGACGTTGTAAAACGACTGGATACTTTGAAACCATTTCC } \\
\text { R: GTTTCCTTACAGATTGCGTTACAATCA }\end{array}$ & (AT) 7 & 185-195 & NED & 2 \\
\hline Tb060TKU & $\begin{array}{l}\text { F: CACGACGTTGTAAAACGACGCAAACTTAATCTTTCTTTTCCAG } \\
\text { R: GTTTATTTTCGCACAGGTTTGCTT }\end{array}$ & (AT) 5 & $215-244$ & PET & 6 \\
\hline Tb061TKU & $\begin{array}{l}\text { F: CACGACGTTGTAAAACGACTGAATGAGTTTTCCAATCAACG } \\
\text { R: GTTTCCTCCACAAATAACCATTAAACC }\end{array}$ & (AT) 5 & $331-357$ & 6-FAM & 4 \\
\hline Tb063TKU & $\begin{array}{l}\text { F: CACGACGTTGTAAAACGACGCAAGTTCTCTTGCCCAAAT } \\
\text { R: GTTTGATGAATCACATAGAAAATCCA }\end{array}$ & (AT) 5 & $181-185$ & NED & 2 \\
\hline Tb046TKU & $\begin{array}{l}\text { F: CACGACGTTGTAAAACGACTGCGGGACTAGTTGTCAGC } \\
\text { R: GTTTGATCCAATCTCTAACACCAA }\end{array}$ & (AT) 7 & 158 & VIC & 1 \\
\hline Tb047TKU & $\begin{array}{l}\text { F: CACGACGTTGTAAAACGACAAGTGCACTAGGAATGGACGA } \\
\text { R: GTTTGGGTTAAAACAATCTCAACATCG }\end{array}$ & (AT) 5 & 307 & NED & 1 \\
\hline Tb048TKU & $\begin{array}{l}\text { F: CACGACGTTGTAAAACGACTCCAATTCTCAAAGATGAAGTTTT } \\
\text { R: GTTTCTGGTGCAATCTGATGCCTA }\end{array}$ & (AT) 5 & 373 & PET & 1 \\
\hline Tb050TKU & $\begin{array}{l}\text { F: CACGACGTTGTAAAACGACTGAGAAAGGCTGGCTATGCT } \\
\text { R: GTTTCAAGGTTCAATTCAATCAATCA }\end{array}$ & (AT) 8 & 172 & VIC & 1 \\
\hline Tb051TKU & $\begin{array}{l}\text { F: CACGACGTTGTAAAACGACCAAAGTGAAACGGTAATAATTTGG } \\
\text { R: GTTTCACTCTCAAATTTATCCTTGTGC }\end{array}$ & (AT) 7 & 423 & NED & 1 \\
\hline Tb053TKU & $\begin{array}{l}\text { F: CACGACGTTGTAAAACGACTGATGCTTCTTTTGGGATATTG } \\
\text { R: GTTTGGCTTCAAGATCATCTCGTC }\end{array}$ & (AT) 5 & 390 & 6-FAM & 1 \\
\hline Tb056TKU & $\begin{array}{l}\text { F: CACGACGTTGTAAAACGACCCCTTTGTTGTTGACCATGA } \\
\text { R: GTTTGGCAAATAAAAACAATTCAAAA }\end{array}$ & (AT) 5 & 394 & PET & 1 \\
\hline Tb062TKU & $\begin{array}{l}\text { F: CACGACGTTGTAAAACGACATCATTCATCCGACCAAACA } \\
\text { R: GTTTCCATTGGTAAGGAATTTGGTT }\end{array}$ & (AT) 5 & 537 & VIC & 1 \\
\hline Tb041TKU & $\begin{array}{l}\text { F: CACGACGTTGTAAAACGACTTGAACCTTTAATTACCATCTGAA } \\
\text { R: GTTTGCCATTTCAAAAGAACGA }\end{array}$ & (AT) 6 & - & 6-FAM & 0 \\
\hline Tb052TKU & $\begin{array}{l}\text { F: CACGACGTTGTAAAACGACGAAGGTATTTCTCATGATTGTGGTC } \\
\text { R: GTTTGAATGCTCAAAAACGATG }\end{array}$ & (AT) 5 & - & PET & 0 \\
\hline Tb057TKU & $\begin{array}{l}\text { F: CACGACGTTGTAAAACGACTGTGAGTGAATGGACGGAAG } \\
\text { R: GTTTAATTCAAAAGAATCAATAGTTGAACA }\end{array}$ & (AT) 5 & - & 6-FAM & 0 \\
\hline Tb064TKU & $\begin{array}{l}\text { F: CACGACGTTGTAAAACGACTCGAAAAATGCATGGGAAAT } \\
\text { R: GTTTGGTTACCATAACCAACTTTTATTTG }\end{array}$ & (AT) 5 & - & PET & 0 \\
\hline
\end{tabular}


most of the sequences in this library were representative of $T$. bryosalmonae. To further check the proportional representation of $F$. sultana and T. bryosalmonae in the genomic library, BLASTn searches with 197 bp sections of putative low-copy number genes (for $T$. bryosalmonae, elongation factor 2 , EF2, and for F. sultana elongation factor alpha-1, $\mathrm{EF} 1 \alpha$ ) were conducted against the paired-end joined MiSeq reads. The number of fragments retrieved for T. bryosalmonae was 323 and 2 for $F$. sultana (in both cases all fragments overlapping the region of interest of identical length were counted). These results suggest that a substantial proportion of the library was dominated by parasite genomic DNA (gDNA) (an estimated $>300 \times$ more parasites than host gDNA). Previous work has shown that di- and trinucleotide repeats in the genome of the bryozoan host, F. sultana, are unusually abundant; thus, even a small amount of host contamination may result in preferential detection of host-associated microsatellite loci (Hartikainen \& Jokela 2012, Schoebel et al. 2013).

Here, we applied an alternative strategy for identification of microsatellite markers in T. bryosalmonae from the same mixed genomic library (Filippenko et al. 2014) by focusing on assembled longer contigs only (500-5449 bp, $\mathrm{n}=9084)$. The focus on longer contigs is expected to increase the likelihood of identification of contigs of $T$. bryosalmonae origin. This is because the material used for library preparation contained only trace amounts of bryozoan host, and thus sequencing coverage over the $T$. bryosalmonae genome should be higher (Filippenko et al. 2014). Due to the positively biased sequencing effort over the likely smaller $T$. bryosalmonae genome we predicted that longer contigs predominantly originate from $T$. bryosalmonae, and we used these to search for microsatellite loci.

Assembly was conducted using SOAPdenovo v.2 (Luo et al. 2012) with kmer size set to 127 . A total of 1226 dinucleotide microsatellite motif (minimum number of repeats $=4$ ) containing sequences were identified using msatcommander v.1.0.8 software. Altogether, 24 dinucleotide microsatellite loci (Table 1, Supplement; available at: www.int-res.com/articles/ suppl/d113p085_supp.pdf) were tested in a panel of $28 \mathrm{~T}$. bryosalmonae-infected brown trout (Salmo trutta) kidney samples and $11 \mathrm{~F}$. sultana samples. Infected kidney samples originated from the following 7 Estonian rivers: Altja, Mustoja, Vainupea, Võsu, Valkla, Keila and Kuusalu (Dash \& Vasemägi 2014). $F$. sultana samples consisted of $8 T$. bryosalmonaeinfected specimens with 3 specimens from both the rivers Avon (Hampshire) and Dun, UK, and single specimens from the rivers Lulaine, France, and Surb, Switzerland). Three bryozoans with no apparent $T$. bryosalmonae infection from the rivers Avon, Dun and Cut, England, were used as controls.

PCR amplifications were performed in $6.1 \mu \mathrm{l}$ total reaction volume, which included ca. 10 to $100 \mathrm{ng}$ of total gDNA, $0.6 \mu \mathrm{M}$ of forward and $1.2 \mu \mathrm{M}$ of reverse primers, $0.5 \mu \mathrm{M}$ of FAM, VIC, NED or PET-labeled universal M13 primer and $3.0 \mu \mathrm{l}$ of $2 \times$ QIAGEN Multiplex Master Mix. Amplification conditions were as follows: initial denaturation at $95^{\circ} \mathrm{C}$ for $15 \mathrm{~min}, 15$ cycles of $30 \mathrm{~s}$ at $94^{\circ} \mathrm{C}, 1 \mathrm{~min} 30 \mathrm{~s}$ at $58^{\circ} \mathrm{C}$, and $60 \mathrm{~s}$ at $72^{\circ} \mathrm{C}_{i}$ followed by 25 cycles of $30 \mathrm{~s}$ at $94^{\circ} \mathrm{C}, 1 \mathrm{~min} 30 \mathrm{~s}$ at $52^{\circ} \mathrm{C}$, and $60 \mathrm{~s}$ at $72^{\circ} \mathrm{C}_{i}$ and a final extension of $10 \mathrm{~min}$ at $60^{\circ} \mathrm{C}$. Fragment analyses were carried out on ABI PRISM 3130xl (Applied Biosystems) with LIZ600 size standard. Genotyping was performed using the software GeneMarker v. 1.6 (Soft Genetics).

In contrast to our previous attempt (Filippenko et al. 2014), 20 of 24 primer pairs successfully amplified microsatellite loci in $T$. bryosalmonae-infected brown trout and bryozoan samples, while no amplification was obtained for non-infected $F$. sultana specimens. Altogether, 12 microsatellite loci were polymorphic (Table 1) with 2 to 6 alleles per locus.

As predicted, the majority of tested microsatellite primers developed from long contigs resulted in positive amplification in $T$. bryosalmonae. Our results suggest that the genomic DNA library was largely biased towards $T$. bryosalmonae and that the genome size of the parasite may be much smaller than that of its bryozoan host, F. sultana. The large discrepancy in microsatellite frequency in the genomes of the 2 organisms may also reflect this genome size difference. Altogether, we developed 12 polymorphic microsatellite loci, but the level of variability of these novel markers was relatively low. It remains to be seen whether the low level of polymorphism found in dinucleotide microsatellite loci is a common feature of $T$. bryosalmonae. The markers developed in the present work will be useful for population genetic studies, characterising dispersal of $T$. bryosalmonae, and examining the epidemiology of PKD.

Acknowledgements. The study was supported by the Academy of Finland (A.V.), Estonian Science Foundation (grant number 8215 to A.V.), the Estonian Ministry of Education and Research (institutional research funding project IUT8-2 to A.V.), Erasmus Mundus research mobility (project 2011467 to D.F.) and molecular research funds from the Natural History Museum, London (H.H., B.O.). 


\section{LITERATURE CITED}

Brownstein MJ, Carpten JD, Smith JR (1996) Modulation of non-templated nucleotide addition by TaqDNA polymerase: primer modifications that facilitate genotyping. Biotechniques 20:1004-1010

Canning EU, Curry A, Feist S, Longshaw M, Okamura B (1999) Tetracapsula bryosalmonae n. sp. for PKX organism, the cause of PKD in salmonid fish. Bull Eur Assoc Fish Pathol 19:203-206

Dash M, Vasemägi A (2014) Proliferative kidney disease (PKD) agent Tetracapsuloides bryosalmonae in brown trout populations in Estonia. Dis Aquat Org 109: 139-148

Filippenko DP, Hartikainen H, Okamura B, Vasemägi A (2014) Characterisation of polymorphic microsatellite loci for the bryozoans Fredericella sultana, the primary host of the causative agent of salmonid proliferative kidney disease. Cons Gen Res 6:481-482

Grabner DS, El-Matbouli M (2010) Tetracapsuloides bryosalmonae (Myxozoa; Malacosporea) portal of entry into the fish. Dis Aquat Org 90:197-208

Hartikainen H, Jokela J (2012) Characterisation of polymorphic microsatellite loci in the freshwater bryozoan Fred-

Editorial responsibility: Dieter Steinhagen,

Hannover, Germany ericella sultana. Cons Gen Res 4:475-477

> Longshaw M, Le Deuff RM, Harris AF, Feist SW (2002) Development of proliferative kidney disease in rainbow trout, Oncorhynchus mykiss (Walbaum), following shortterm exposure to Tetracapsula bryosalmonae infected bryozoans. J Fish Dis 25:443-449

> Luo R, Liu B, Xie Y, Li Z, and others (2012) SOAPdenovo2: an empirically improved memory-efficient short-read de novo assembler. GigaScience 1:18

$>$ Morris DJ, Adams A, Richards RH (2000) In situ hybridisation identifies the gill as a portal of entry for PKX (Phylum Myxozoa), the causative agent of proliferative kidney disease in salmonids. Parasitol Res 86:950-956

- Okamura B, Hartikainen H, Schmidt-Posthaus H, Wahl T (2011) Life cycle complexity, environmental change and the emerging status of salmonid proliferative kidney disease. Freshw Biol 56:735-753

Schoebel CN, Brodbeck S, Buehler D, Cornejo C, Gajurel J, Hartikainen H, Csencsics D (2013) Lessons learned from microsatellite development for nonmodel organisms using 454 pyrosequencing. J Evol Biol 26:600-611

> Skovgaard A, Buchmann K (2012) Tetracapsuloides bryosalmonae and PKD in juvenile wild salmonids in Denmark. Dis Aquat Org 101:33-42

Submitted: August 4, 2014; Accepted: December 4, 2014 Proofs received from author(s): January 5, 2015 